\title{
Characterization of earth fissures in South Jiangsu, China
}

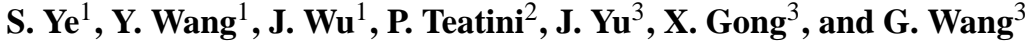 \\ ${ }^{1}$ School of Earth Sciences and Engineering, Nanjing University, Nanjing, China \\ ${ }^{2}$ Department of Civil, Environmental and Architectural Engineering, University of Padova, Padova, Italy \\ ${ }^{3}$ Key Laboratory of Earth Fissures Geological Disaster, Ministry of Land and Resources, (Geological Survey of \\ Jiangsu Province), Nanjing, China \\ Correspondence to: S. Ye (sjye@nju.edu.cn) \\ Published: 12 November 2015
}

\begin{abstract}
The Suzhou-Wuxi-Changzhou (known as "Su-Xi-Chang") area, located in the southern part of Jiangsu Province, China, experienced serious land subsidence caused by overly exploitation of groundwater. The largest cumulative land subsidence has reached $3 \mathrm{~m}$. With the rapid progress of land subsidence since the late 1980s, more than 20 earth fissures developed in Su-Xi-Chang area, although no pre-existing faults have been detected in the surroundings. The mechanisms of earth fissure generation associated with excessive groundwater pumping are: (i) differential land subsidence, (ii) differences in the thickness of the aquifer system, and (iii) bedrock ridges and cliffs at relatively shallow depths. In this study, the Guangming Village Earth Fissures in Wuxi area are selected as a case study to discuss in details the mechanisms of fissure generation. Aquifer exploitation resulted in a drop of groundwater head at a rate of $5-6 \mathrm{~m} \mathrm{yr}^{-1}$ in the 1990s, with a cumulative drawdown of $40 \mathrm{~m}$. The first earth fissure at Guangming Village was observed in 1998. The earth fissures, which developed in a zone characterized by a cumulative land subsidence of approximately $800 \mathrm{~mm}$, are located at the flank of a main subsidence bowl with differential subsidence ranging from 0 to $1600 \mathrm{~mm}$ in 2001 . The maximum differential subsidence rate amounts to $5 \mathrm{~mm} \mathrm{yr}^{-1}$ between the two sides of the fissures. The fissure openings range from 30 to $80 \mathrm{~mm}$, with a cumulative length of $1000 \mathrm{~m}$. Depth of bed rock changes from 60 to $140 \mathrm{~m}$ across the earth fissure. The causes of earth fissure generation at Guangming Village includes a decrease in groundwater levels, differences in the thickness of aquifer system, shallow depths of bedrock ridges and cliffs, and subsequent differential land subsidence.
\end{abstract}

\section{Introduction}

Excessive exploitation of groundwater in Suzhou-WuxiChangzhou (known as "Su-Xi-Chang") area, located in the southern part of Jiangsu Province, China, started in the 1970s. It has resulted in serious land subsidence and earth fissure hazard that caused significant damage and heavy economic losses. The first earth fissure case in the Su-Xi-Chang area was reported in 1989 at Henglin town of Changzhou City. Twenty earth fissures occurred in the Su-Xi-Chang area between 1990 and 2000. The rapid development of earth fissures from 1990 to 2000 destroyed many buildings and the local governments decided to stop groundwater pumping in 2000 to alleviate land subsidence and earth fissures.
Currently, a total of 25 earth fissures have been found in $\mathrm{Su}$-Xi-Chang area, mainly located in the Wujin County in Changzhou and Xishan County in Wuxi (Fig. 1) (Liu et al., 2004). According to geological surveys, the orientation of the earth fissure in this area are mainly NE (NNE), EW and SN direction (Fig. 1), showing no obvious unified direction in the region. All the fissures are in a dense banded distribution and their orientation are in perfect accordance with the underlying bedrock. The width of the earth fissure zone generally ranges from 30 to $100 \mathrm{~m}$, and the length varies between 200 and $600 \mathrm{~m}$, and several fissures can reach lengths of $1000 \mathrm{~m}$ (Yu et al., 2004).

A significant amount of research has been done to study the occurrence of earth fissures in this area. Liu et al. (2004) 


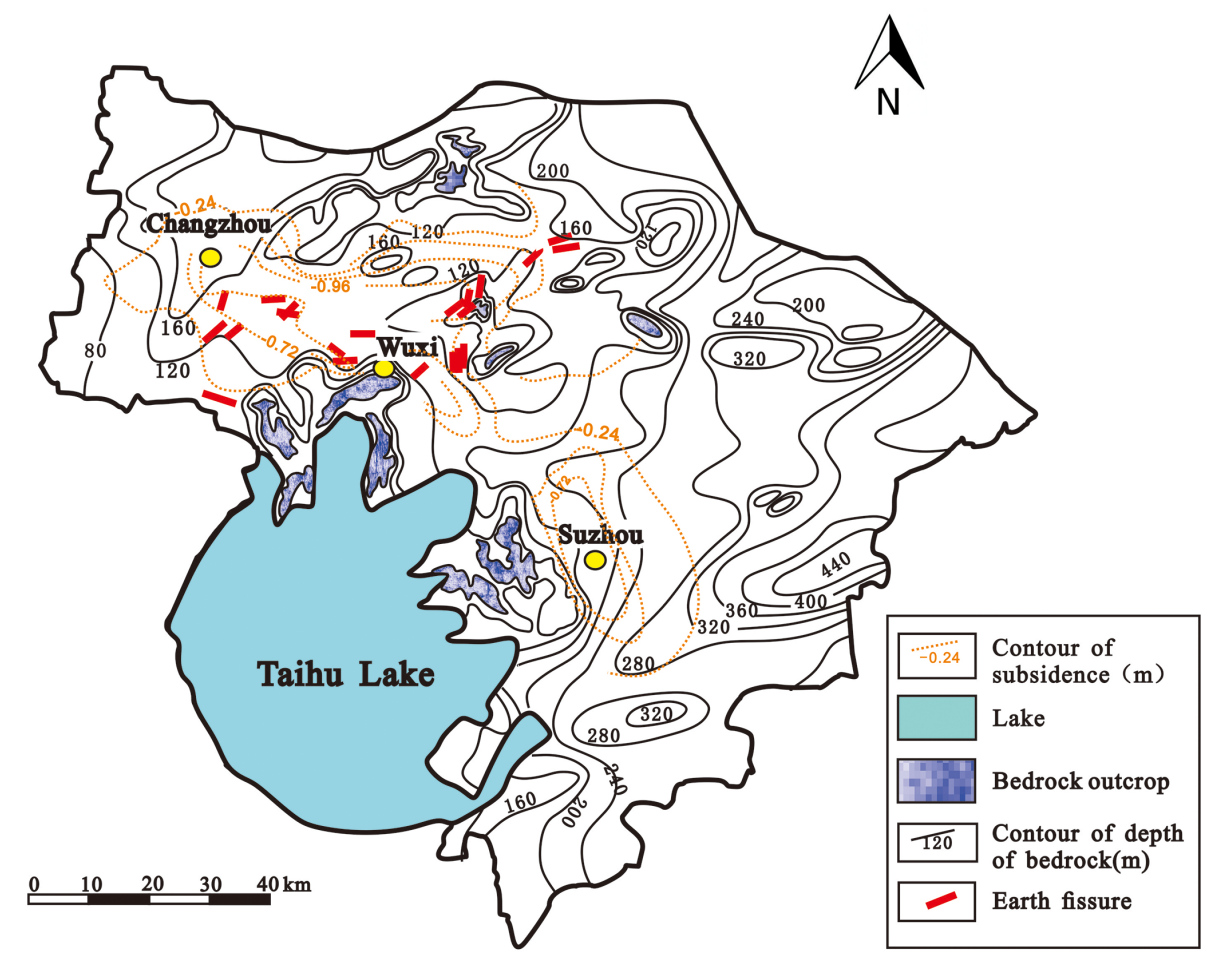

Figure 1. The distribution of earth fissures in Su-Xi-Chang area. The bedrock outcrops and depth (m from the mean sea level) and the cumulative land displacement from 1980 to 2000 are mapped (after Liu et al., 2004).
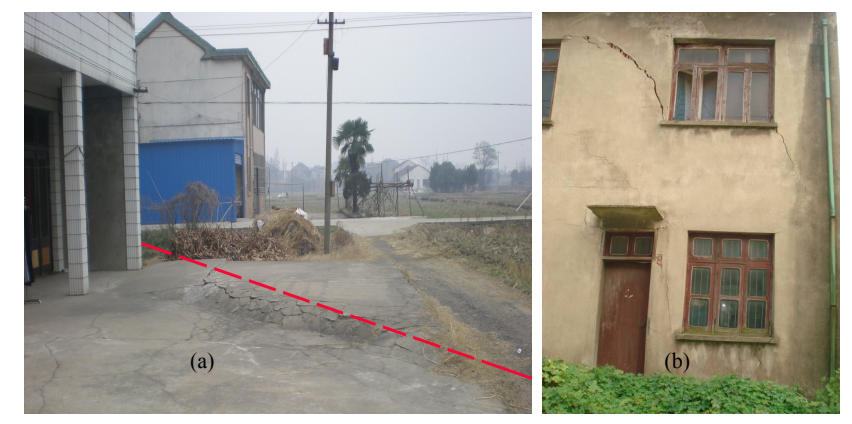

Figure 2. The ground rupture (a) and damaged house (b) at Guangming Village (red line in (a) shows the direction of the earth fissure).

identified the factors related to the development of earth fissure including bedrock hills, buried terraces, Karst collapse, structural differences of the aquifer system, and overexploitation of groundwater. Wang et al. $(2009,2010)$ reported earth fissures triggered by excessive groundwater withdrawal and the variability of bedrock depth in Hetang town, Jiangyin City. Yu et al. (2006) analyzed the mechanisms leading to occurrence of some typical earth fissures using three-dimensional seismic exploration techniques. Based on the inversion of the 3-D seismic data, the sedimentary structure and morphology of the bedrock surface were obtained. Yu et al. (2004) reported that earth fissures in the $\mathrm{Su}-\mathrm{Xi}-\mathrm{Chang}$ area develop under the combined effects of the visco-elasto-plastic deformation of some sedimentary layers, buried bedrock surface morphology, thickness differences of some highly compressible sedimentary layers, and excessive exploitation of groundwater.

In Su-Xi-Chang area, the second confined aquifer was the main over-exploited unit. Groundwater pumping has formed a large, wide ranging cone of land subsidence because of long term over-exploitation of groundwater. The groundwater levels in the drawdown cone declined to $-80 \mathrm{~m}$ in $1990 \mathrm{~s}$, and the largest cumulative subsidence was close to $2000 \mathrm{~mm}$ (Zhang et al., 2008). The groundwater levels recovered gradually from the previous lowest value to about $-75 \mathrm{~m}$ in 1994 and $-58 \mathrm{~m}$ in 2003 , since the implementation of severe restrictions of groundwater exploitation by the Jiangsu government in 1995 (Zhang et al., 2008). The Jiangsu government finally decided to prohibit all groundwater exploitation in the Su-Xi-Chang area from 2000. As a result, land subsidence became controlled in some areas, and the rate of land subsidence decreased from $110 \mathrm{~mm} \mathrm{yr}^{-1}$ in 1994 to $10-0 \mathrm{~mm} \mathrm{yr}^{-1}$ in 2006 (Wang et al., 2009). The movement rates for these fissures slowed gradually, and the number of earth fissure are no longer increasing except for a few active earth fissures. The most active fissures in Su-Xi-Chang area are located in the Guangming Village, Xishan District of Wuxi City, with the maximum subsidence rate of about $5 \mathrm{~mm} \mathrm{yr}^{-1}$. 

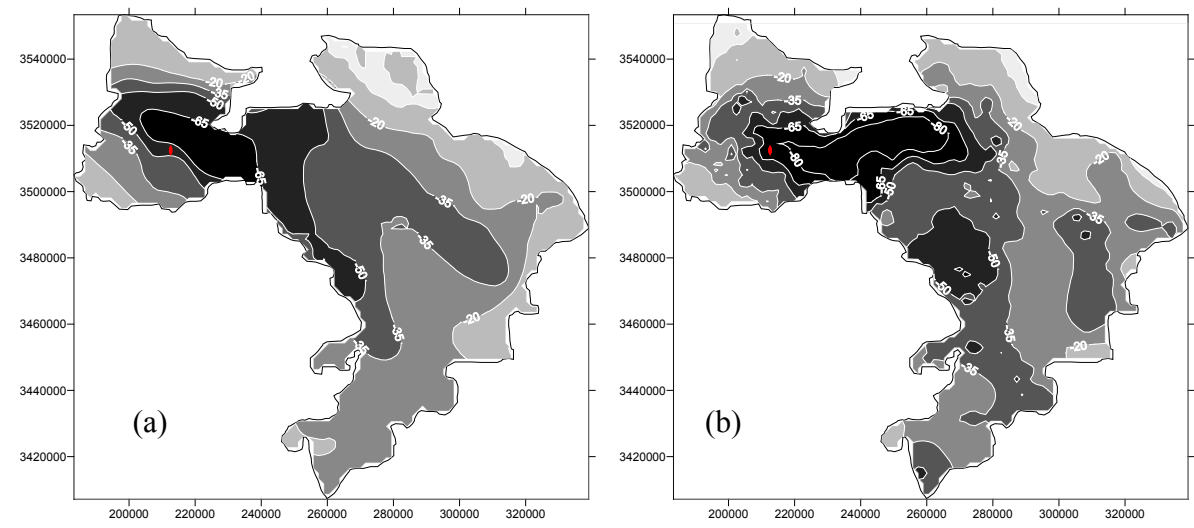

Figure 3. Groundwater level ( $\mathrm{m}$ above mean sea level) in the second confined aquifer in 1995 (a) and 2001 (b). The red line represents the earth fissure at Guangming Village.
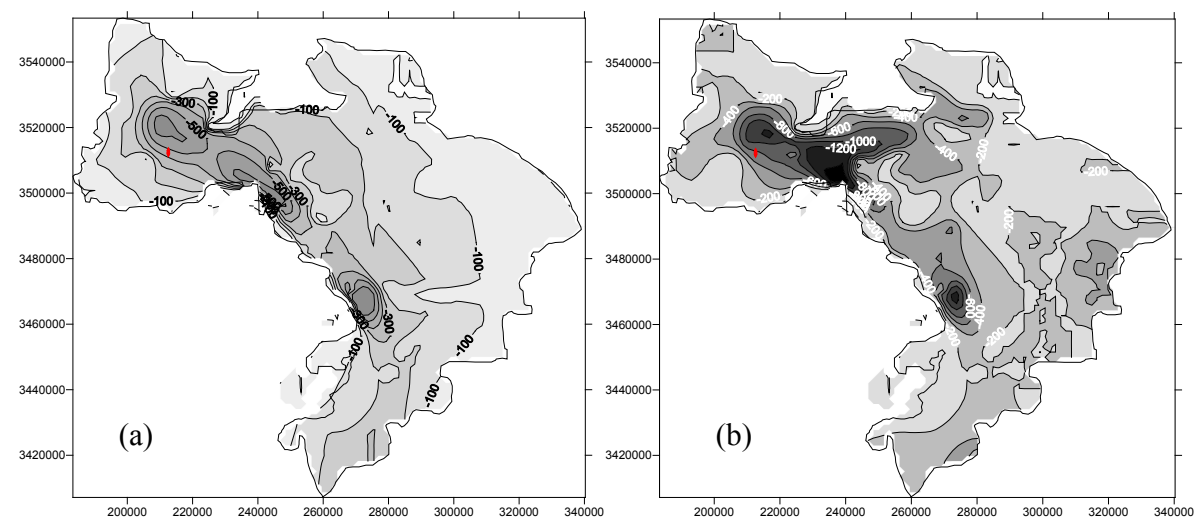

Figure 4. Cumulative land subsidence (mm) from 1980 to 1995 (a) and 2001 (b). The red line represents the earth fissure at Guangming Village.

\section{Earth fissures at Guangming Village}

The first earth fissure at Guangming Village was discovered in 1998. Earth fissuring advanced significantly since 2000, with tilting farmlands and ground fractures at the early stages of development. Fissuring increased drastically since 2007 with more than 400 newly damaged houses (Fig. 2). The orientation of the earth fissures at Guangming Village are mostly in NE direction which is along the ridge tip.

\section{Regional and local groundwater levels}

The second confined aquifer is the main withdrawn aquifer in the Su-Xi-Chang area. Groundwater was overly exploited in the 1990s, and the total pumped groundwater reached 380 million $\mathrm{m}^{3}$ in 1995 . The groundwater levels in the second confined aquifer dropped from -35 to $-75 \mathrm{~m}$, with values between -60 and $-55 \mathrm{~m}$ at Guangming Village (Fig. 3a). The total pumping rate decreased from 1996 to 2000 to 250 million $\mathrm{m}^{3}$ in 2000 . The groundwater exploitation was prohibited after 2001 in the Su-Xi-Chang area. However, the groundwater levels in some areas still continued to drop. For example, the groundwater levels in the second confined aquifer dropped to $-95 \mathrm{~m}$ in the center of the drawdown cone and the groundwater level at Guangming Village ranged from -75 to $-70 \mathrm{~m}$ (Fig. 3b).

\section{Regional and local cumulative land subsidence}

The lowering of the groundwater levels resulted in a severe land subsidence. The cumulative land subsidence in 1995 reached to $700 \mathrm{~mm}$ at the center of the subsidence bowl surrounding Guangming Village, and between $400-500 \mathrm{~mm}$ at Guangming Village (red line in Fig. 4a). The cumulative land subsidence in 2001 peaked to $1600 \mathrm{~mm}$ at the center of subsidence bowl located about $20 \mathrm{~km}$ to the east of the Guangming Village, and to $700-800 \mathrm{~mm}$ at Guangming Village (Fig. 4b). From the regional cumulative land subsidence maps, one can see that earth fissures in Guangming Village are in the middle of the subsiding area. 


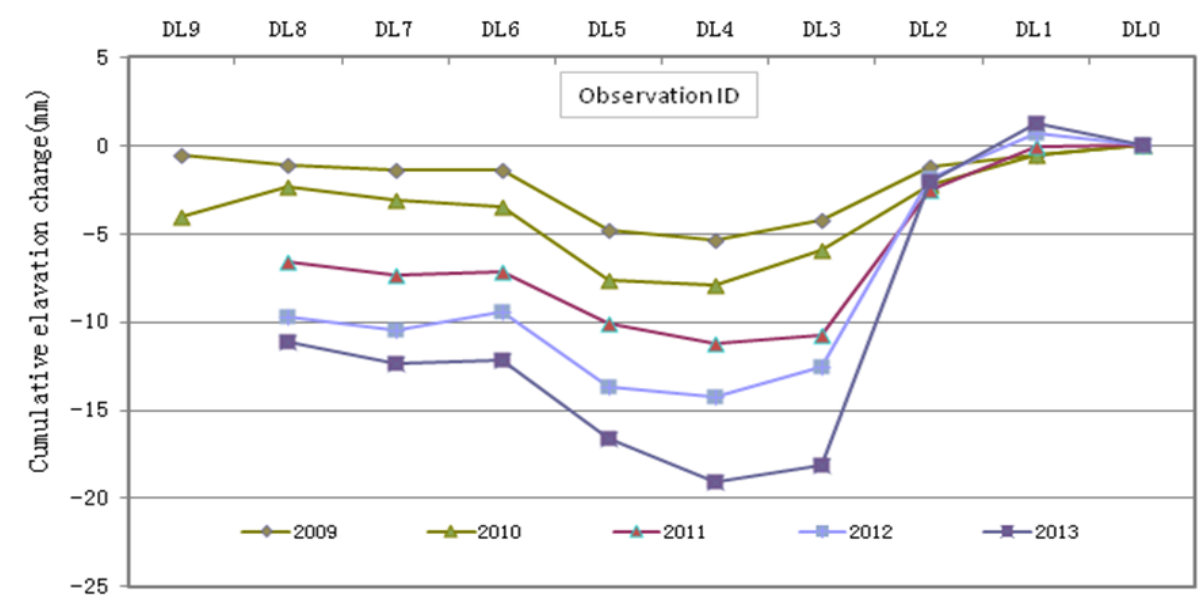

Figure 5. Cumulative elevation changes from 2009 to 2013 at the ten leveling benchmarks established across the fissure at Guangming Village. DL0 is used as reference point. The distance between DL0 and DL9 is approximately $80 \mathrm{~m}$.
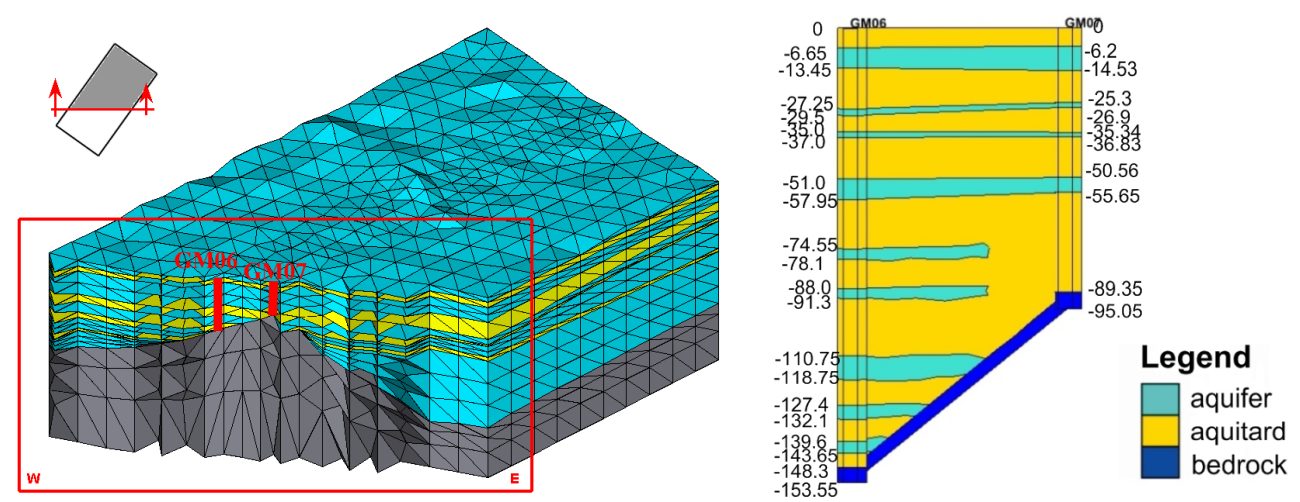

Figure 6. Perspective view of the Finite-Element model developed by Franceschini et al. (2015) to simulate the earth fissure generation at Guangming Village (a). The geological setting is highlighted in various colours: rock in grey, aquifers in yellow, and aquitards in blue). Hydrogeological profile between boreholes GM06 and GM07 (b). The numbers provide the buried depths of the top of each layer.

\section{Local differential land subsidence}

The farmland is obviously tilting at Guangming Village, which signifies the occurrence of differential land subsidence. Ten leveling points were established in 2007 along a trail that crosses one of the earth fissures. Because no deep stable benchmark was set at Guangming Village, the leveling benchmark DL0 is used as a reference point. The other 9 levelling points show a significant different elevation compared to DL0 (Fig. 5) over the monitoring interval from 2009 to 2013. Benchmark DL4 always shows the highest land subsidence values, and the average differential land subsidence is $5 \mathrm{~mm} \mathrm{yr}^{-1}$.

\section{Geological setting with buried rock ridge}

The thickness of the aquifer system in the Su-Xi-Chang area is not uniform because of buried rock ridges whose depth varies significantly in some local areas. Due to this peculiar geological setting, the thickness of the aquifer system clearly differs across the rock ridges, with thicker sediments further away from ridge (Fig. 6a). For example, the thickness of the aquifer system at borehole GM07 is $95 \mathrm{~m}$ and that at GM06, only $95 \mathrm{~m}$ apart, is $153 \mathrm{~m}$ (Fig. 6b). The hydrostratigraphic section in Fig. $6 \mathrm{~b}$ also shows that there are more aquifers at GM06 than at GM07.

\section{Conclusions}

Earth fissures are serious problems in Su-Xi-Chang area. They are distributed along the buried rock ridge primarily in the main NE direction. Excessive groundwater exploitation triggers earth fissuring. Earth fissuring at Guangming Village typically demonstrates the causes and mechanism of earth fissure generation and development, which includes groundwater level decrease, buried rock ridges with differing depths, the heterogeneous aquifer system, and subsequent differential land subsidence. A numerical model to simulate 
the generation and development of earth fissures at Guangming Village is being developed (Franceschini et al., 2015).

Acknowledgements. Funding supported by the Special Project for the Public Scientific Research of the Ministry of Land and Resources of China No. 201411096, KLEFGD No. 201403, NSFC No. 41272259 and NSF of Jiangsu Province No. BK2012730 is appreciated. Pietro Teatini was partially supported by the University of Padova, Italy, within the 2014 International Cooperation Programme. The international collaboration is supported by UNESCO IGCP Project No. 641 (M3EF3 - Deformation and fissuring caused by exploitation of subsurface fluids).

\section{References}

Franceschini, A., Teatini, P., Janna, C., Ferronato, M., Gambolati, G., Ye, S., and Carreon-Freyre, D., Modelling ground rupture due groundwater withdrawal: applications to test cases in China and Mexico, Proceeding of the Ninth International Symposium on Land Subsidence, Nagoya, November 2015.
Liu, C., Yuan, X. J., and Zhu, J. Q.: Earth fissures in Su-Xi-Chang area, China University of Geosciences Press, 2004 (in Chinese).

Wang, G. Y., You, G., Shi, B., Yu, J., Li, H. Y., and Zong, K. H. : Earth fissures triggered by groundwater withdrawal and coupled by geological structures in Jiangsu Province, China, Environ. Geol., 57, 1047-1054, 2009.

Wang, G. Y., You, G., Shi, B., Qiu, Z. L., Li, H. Y., and Tuck, M.: Earth fissures in Jiangsu Province, China and geological investigation of Hetang earth fissure, Environ. Earth Sci., 60, 35-43, 2010.

Yu, J., Wang, X., Su, X., and Yu, Q.: The mechanism analysis on ground failure disaster formation in Suzhou- Wuxi - Changzhou area, Journal of Jilin University (Earth Science Edition), 34, 236241, 2004 (in Chinese).

Yu, J., Chen, G, Wang, X. M., He, H. S., Xu, X. L., and Wu, J. H.: Formation mechanisms analysis on ground failure based on 3D seismic exploration data in Yinguo'an area, Hydrogeology \& Engineering Geology, 34, 117-123, 2006 (in Chinese).

Zhang, Y., Xue, Y. Q, Wu, J. C., Yu, J., Wei, Z. X., and Li, Q. F.: Land subsidence and earth fissures due to groundwater withdrawal in the Southern Yangtse Delta, China, Environ. Geol., 55, 751-762, 2008. 